\title{
Coeficiente de repetibilidade e parâmetros genéticos em capim-elefante
}

\author{
Marcelo Cavalcante(1), Mário de Andrade Lira ${ }^{(2)}$, Mércia Virgínia Ferreira dos Santos ${ }^{(1)}$, \\ Eduardo Bruno Afonso Ferreira Pita ${ }^{(1)}$, Rinaldo Luiz Caraciolo Ferreira( ${ }^{(3)}$ e José Nildo Tabosa ${ }^{(2)}$
}

\begin{abstract}
(1)Universidade Federal Rural de Pernambuco (UFRPE), Departamento de Zootecnia, Rua Dom Manoel de Medeiros, Dois Irmãos, CEP 52171-900 Recife, PE. E-mail: marcelo.agronomia@gmail.com, mercia@dz.ufrpe.br, brunoapita@gmail.com (2)Instituto Agronômico de Pernambuco, Avenida General San Martin, no 1.371, Bongi, CEP 50761-000 Recife, PE. E-mail: mariolira@terra.com.br, nildo.tabosa@ipa.br ${ }^{(3)}$ UFRPE, Departamento de Ciência Florestal. E-mail: rinaldo@dcfl.ufrpe.br
\end{abstract}

Resumo - O objetivo deste trabalho foi determinar os coeficientes de repetibilidade de caracteres morfofisiológicos em genótipos de capim-elefante (Pennisetum spp.), a partir de dados obtidos durante seis ciclos de avaliação. Foram estimados: número mínimo de medições e parâmetros genéticos. Utilizou-se o delineamento experimental de blocos ao acaso, em arranjo de parcelas subdivididas, com quatro níveis de $\mathrm{N}$ (controle, 30, 60 e $90 \mathrm{~kg} \mathrm{ha}^{-1}$ por corte) e 16 genótipos de Pennisetum (11 híbridos interespecíficos e cinco cultivares). Os ciclos consistiram de avaliações em 2010 (21/4, 19/7 e 28/9) e 2011 (6/1, 7/4 e 3/8). Os coeficientes de repetibilidade foram de média-alta magnitude para todas as variáveis, o que indica que houve regularidade entre as medidas repetidas. Para as variáveis massa de forragem, altura da planta, comprimento e largura da folha, diâmetro do colmo, clorose e índice de área foliar, três ciclos de avaliação são suficientes para obter $\mathrm{R}^{2}$ de $90 \%$, pela análise de componentes principais. Para o comprimento do entrenó, o mínimo de sete avaliações é necessário para predizer o valor real dos genótipos. Os parâmetros genéticos das variáveis massa de forragem, comprimento e largura da folha, diâmetro do colmo e clorose foliar são de alta magnitude, o que favorece a seleção de genótipos superiores de Pennisetum.

Termos para indexação: Pennisetum purpureum, componentes principais, herdabilidade.

\section{Coefficient of repeatability and genetic parameters in elephant grass}

\begin{abstract}
The objective of this work was to determine the coefficients of repeatability of morphophysiological traits in elephant grass (Pennisetum spp.) genotypes, from data obtained during six evaluation cycles. The minimum number of measurements and genetic parameters were estimated. The experiment design was a randomized complete block, in a split-plot arrangement, with four $\mathrm{N}$ levels (control, 30, 60, and $90 \mathrm{~kg} \mathrm{ha}^{-1}$ per cut) and 16 Pennisetum genotypes (11 interspecific hybrids and five cultivars). The cycles consisted of evaluations in 2010 (4/21, 7/19, and $9 / 28)$ and $2011(1 / 6,4 / 7$, and 8/3). The coefficients of repeatability were of medium-high magnitude for all variables, indicating that there was regularity between repeated measures. For the variables forage mass, plant height, leaf length and width, stem diameter, leaf chlorosis and area index, three cycles of evaluation are enough to reach $\mathrm{R}^{2}$ of $90 \%$ by principal component analysis. For internode length, the minimal of seven evaluations is necessary to predict the true value of genotypes. The genetic parameters of the variables forage mass, leaf length and width, stem diameter and leaf chlorosis are of high magnitude, favoring the selection of superior Pennisetum genotypes.
\end{abstract}

Index terms: Pennisetum purpureum, principal components, heritability.

\section{Introdução}

Nas regiões tropicais, a utilização do capim-elefante (Pennisetum purpureum Schum.) e de seus clones (Pennisetum spp.) em forma de capineira, sob irrigação, constitui prática promissora e bastante difundida, por seu potencial de acúmulo de forragem, que varia de acordo com o genótipo e o ambiente no qual está inserido. Quando cultivado com disponibilidade hídrica satisfatória e manejado intensivamente, o capim-elefante pode atingir produções diárias superiores a $125 \mathrm{~kg} \mathrm{ha}^{-1}$ de matéria seca (Paciullo et al., 2003).
O melhoramento da maioria das características de importância forrageira do capim-elefante pode ser conseguido por meio da exploração da variabilidade existente na própria espécie que, segundo Cavalcante \& Lira (2010), é de alta magnitude. As estratégias de melhoramento consistem em hibridações intraespecíficas e interespecíficas (capim-elefante $\mathrm{x}$ milheto), bem como na seleção clonal (Lira et al., 2010), as quais são utilizadas para a seleção de genótipos superiores quanto às características: alta produtividade, resistência a insetos-praga (cigarrinha-das-pastagens, Zulia entreriana) e doenças (mancha ocular, 
Helminthosporium sacchari), resistência ao pisoteio, tolerância à seca, ao alumínio e à salinidade, maior teor de matéria seca, maior digestibilidade (Ferreira \& Pereira, 2005), e, mais recentemente, maior teor de lignina e de celulose, para a produção de biocombustível sólido (Morais et al., 2009).

Em programas de melhoramento genético, ao selecionar um genótipo, espera-se que sua superioridade inicial perdure durante toda a sua vida. De acordo com Cruz \& Regazzi (2001), a veracidade dessa expectativa poderá ser comprovada pelo coeficiente de repetibilidade (r). Este parâmetro mede a capacidade de os organismos repetirem a expressão do caráter ao longo de vários períodos de tempo, no decorrer de suas vidas (Resende, 2002). Altos valores desse coeficiente, para quaisquer características, indicam que é possível predizer o valor real dos indivíduos com base em determinado número de medições (Martuscello et al., 2007).

O conhecimento de parâmetros genéticos, tais como: herdabilidade no sentido amplo $\left(\mathrm{h}^{2}\right)$, importante para espécies propagadas vegetativamente, em que o genótipo é herdado integralmente por seus descendentes (Resende, 2002); coeficiente de variação genético $\left(\mathrm{CV}_{\mathrm{G}}\right)$ e índice de variação (b), os quais controlam um determinado caráter, são de grande importância para o pesquisador, uma vez que orientam na escolha do método de melhoramento mais adequado à cultura, $\mathrm{o}$ que maximiza ganhos com a seleção (Cruz \& Regazzi, 2001).

O objetivo deste trabalho foi determinar os coeficientes de repetibilidade de caracteres morfofisiológicos em genótipos de Pennisetum spp., a partir de dados obtidos durante seis ciclos de avaliação.

\section{Material e Métodos}

O experimento foi instalado em 2009 na Estação Experimental do Instituto Agronômico de Pernambuco (IPA), localizada no Município de Itambé $\left(7^{\circ} 25^{\prime} \mathrm{S}\right.$ e $35^{\circ} 06^{\prime} \mathrm{W}$, a $190 \mathrm{~m}$ de altitude), na microrregião fisiográfica da Mata Seca de Pernambuco. O solo da área foi classificado como Argissolo Vermelho-Amarelo distrófico, com horizonte A proeminente de textura média/argilosa, fase floresta tropical subcaducifólia (Beltrão et al., 2005). A precipitação pluvial total durante o período experimental foi de $2.663,4 \mathrm{~mm}$, que superou a média histórica $(2.575,0 \mathrm{~mm})$. A precipitação mensal observada, bem como a precipitação mensal histórica, conforme dados obtidos na Estação Experimental do IPA (Instituto de Tecnologia de Pernambuco, 2011), estão descritas na Figura 1.

Foram avaliados dez novos híbridos interespecíficos provenientes do cruzamento entre o capim-elefante e o milheto, cinco cultivares de capim-elefante, além de um híbrido interespecífico desenvolvido e cultivado pelo IPA (Tabela 1), sob quatro níveis de N.

Utilizou-se o delineamento de blocos ao acaso, com três blocos, em arranjo de parcelas subdivididas, tendose considerado, nas parcelas principais, os níveis de $\mathrm{N}$ (controle, 30,60 e $90 \mathrm{~kg} \mathrm{ha}^{-1}$ por corte, na forma de ureia), e, nas subparcelas, 16 genótipos de Pennisetum spp. A unidade experimental foi composta por touceira, em razão da limitada disponibilidade de colmos-semente na ocasião da instalação do experimento. Em cada parcela principal, foi feita bordadura com a cultivar IRI 381.

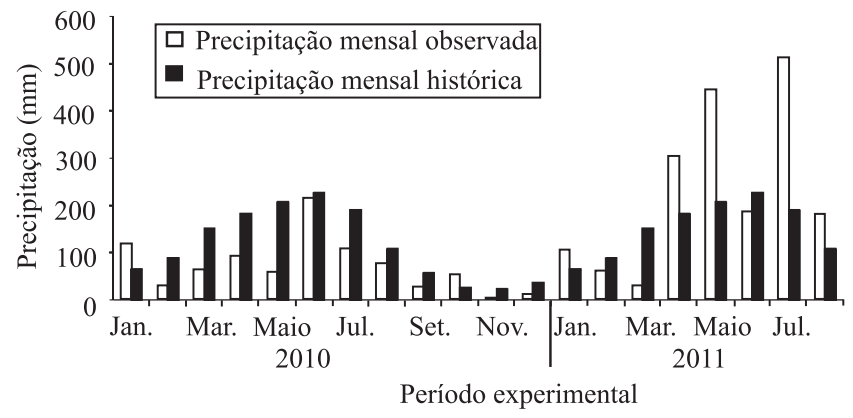

Figura 1. Precipitação (mm) em Itambé, PE, durante o período experimental com base nos dados obtidos no Instituto de Tecnologia de Pernambuco (2011).

Tabela 1. Cruzamentos interespecíficos de capim-elefante com milheto, número de progênies geradas e cultivares avaliadas.

\begin{tabular}{lcc}
\hline Cruzamento interespecífico & № de progênies & Híbridos novos \\
\hline Pioneiro x IPA Bulk-1 (1) & 3 & IPA-1, IPA-7, IPA-8 \\
Elefante B x IPA Bulk-1 & 3 & IPA-A2, IPA-A4, IPA-A5 \\
IRI 381 x IPA Bulk-1 & 2 & IPA-B1, IPA-B3 \\
Taiwan A-146 x IPA Bulk-1 & 2 & IPA-C8, IPA-C9 \\
Elefante B x 23A(1) & 1 & HV 241 (híbrido cultivado) \\
\hline Cultivares & & - \\
$\quad$ Mineirão & 1 & - \\
$\quad$ Taiwan A-146 & 1 & - \\
$\quad$ Elefante B & 1 & - \\
$\quad$ IRI 381 & 1 & \\
Pioneiro & 1 & \\
Total & 16 & \\
\hline
\end{tabular}

${ }^{(1)}$ Cultivar de milheto. 
A análise química do solo, na camada de 0 a 0,20 m, indicou: $\mathrm{pH}$ em $\mathrm{H}_{2} \mathrm{O}$ de 4,$9 ; 10 \mathrm{mg} \mathrm{dm}^{-3}$ de $\mathrm{P} ; 0,66 \mathrm{cmol}_{\mathrm{c}} \mathrm{dm}^{-3}$ de $\mathrm{Ca} ; 0,23 \mathrm{cmol}_{\mathrm{c}} \mathrm{dm}^{-3} \mathrm{de}$ $\mathrm{Mg} ; 0,07 \mathrm{cmol}_{\mathrm{c}} \mathrm{dm}^{-3}$ de $\mathrm{K} ; 1,3 \mathrm{cmol}_{\mathrm{c}} \mathrm{dm}^{-3}$ de $\mathrm{Al}$; e 4,96 $\mathrm{cmol}_{\mathrm{c}} \mathrm{dm}^{-3} \mathrm{de} \mathrm{H}$. Foram aplicados 5,0 $\mathrm{Mg} \mathrm{ha}^{-1} \mathrm{de}$ calcário dolomítico [PRNT $=75,6 \%$; saturação por bases desejada $\left(\mathrm{V}_{2}\right)=65 \%$ ] 60 dias antes do plantio, que foi realizado entre 5 e 9 de maio de 2009, no espaçamento de 2,0x1,0 m (2,0 $\mathrm{m}^{2}$ por touceira). Foram realizados replantios, principalmente dos novos híbridos, em virtude da dificuldade de estabelecimento desses genótipos, o que resultou em plantas com diferentes idades ontogênicas no mesmo tratamento. Aos 60 dias após o plantio, foram realizadas as adubações fosfatada (44 $\mathrm{kg} \mathrm{ha}^{-1}$ de $\mathrm{P}$; superfosfato simples) e potássica (66 $\mathrm{kg} \mathrm{ha}^{-1}$ de K; cloreto de potássio). Em 27/1/2010, foi realizado um corte de uniformização rente ao solo e, em seguida, foram aplicados os tratamentos nitrogenados. Todos os adubos foram incorporados ao solo com auxílio de enxada.

Foram avaliadas as variáveis massa de matéria seca de forragem (folha + colmo) ( $\mathrm{kg}$ por touceira), altura da planta $(\mathrm{m})$, comprimento da folha $(\mathrm{cm})$, largura da folha ( $\mathrm{mm})$, diâmetro do colmo ( $\mathrm{mm})$ e comprimento do entrenó (mm), nos 16 genótipos de Pennisetum spp., em seis ciclos (CI) de avaliação, dos quais três foram realizados em $2010(21 / 4,19 / 7$ e 28/9) e três em 2011 (6/1, 7/4 e 3/8). Em cada avaliação (corte), foram aplicados os tratamentos nitrogenados, juntamente com a adubação de manutenção de $66 \mathrm{~kg} \mathrm{ha}^{-1}$ de K, com cloreto de potássio (Santos et al., 2008).

A forragem foi cortada rente ao solo e pesada no campo, e uma fração de cada touceira (três perfilhos) foi levada ao laboratório para secagem em estufa de ventilação forçada, a $65^{\circ} \mathrm{C}$ por 72 horas, para posterior determinação da massa de matéria seca de forragem ( $\mathrm{kg}$ por touceira por corte). A altura da planta foi obtida com uso de trena, a partir da base do perfilho mais desenvolvido até a inflexão da folha mais alta. Tanto o comprimento quanto a largura da folha foram mensurados na primeira folha completamente expandida (aquela que apresentou a lígula completamente exposta), com uso de trena e paquímetro, respectivamente. $\mathrm{O}$ diâmetro do colmo e o comprimento do entrenó foram mensurados no segundo entrenó a partir do solo (média de três perfilhos por touceira), com auxílio de paquímetro.
Foram realizadas avaliações da clorose foliar, com uso do equipamento SPAD 502 (Konica Minolta, Osaka, Japão), em pontos situados na metade da folha completamente expandida, a partir da base de uma das margens da folha. Para obter um valor representativo da touceira, foram realizadas leituras nos estratos basal, mediano e superior, com dez leituras por estrato, o que totalizou 30 medições por touceira. Com o auxílio do equipamento LAI 2000 (LI-COR, Lincoln, NE, EUA), foram realizadas avaliações do índice de área foliar (IAF), com uma leitura sobre a copa e quatro leituras na região basal da touceira, a $10 \mathrm{~cm}$ de altura do solo e da touceira.

Os dados foram analisados como medidas repetidas no tempo, com uso dos modelos mistos por meio do PROC MIXED (SAS Institute, 2008). Os dados de todas as variáveis foram ajustados pela matriz de variância (VC), por meio do menor valor no critério de informação de Akaike (AIC). As médias foram obtidas pelo ajuste dos efeitos fixos por meio do comando LSMEANS do SAS.

Uma vez que as estimativas da repetibilidade variam de acordo com a natureza da variável, com as propriedades genéticas dos genótipos e com as condições nas quais as plantas são cultivadas, foram obtidos coeficientes de repetibilidade com base em quatro métodos distintos, descritos por Cruz \& Regazzi (2001): modelo da análise de variância (ANOVA); componentes principais obtidos a partir de matrizes de covariância (CPCOV) ou de correlação (CPCOR); e análise estrutural, determinada com base no autovalor teórico da matriz de correlação (AECOR), para maior confiabilidade nas estimativas obtidas. Pelo método da ANOVA, tendo-se considerado que o número de medidas repetidas foi igual para todos os genótipos, adotou-se o Modelo 2, descrito por Cruz \& Regazzi (2001): $Y_{\mathrm{ij}}=\mu+\mathrm{G}_{\mathrm{i}}+\mathrm{A}_{\mathrm{j}}+\varepsilon_{\mathrm{ij}}$, em que: $\mathrm{Y}_{\mathrm{ij}}$ é média do i-ésimo genótipo no j-ésimo ciclo; $\mu$ é a média geral do experimento; $\mathrm{G}_{\mathrm{i}}$ é o efeito do i-ésimo genótipo sob a influência do ambiente permanente; $A_{j}$ corresponde ao efeito do A-ésimo ciclo; e $\varepsilon_{\mathrm{ij}}$ corresponde ao erro aleatório que envolve outras causas de variação não incluídas no modelo.

O número mínimo de medições necessárias nos caracteres avaliados para predizer o seu valor real, com base em coeficientes de determinação $\left(\mathrm{R}^{2}\right)$ pré-estabelecidos $(0,80,0,85,0,90$ e 0,95$)$, foi calculado pela expressão: $\eta=R^{2}(1-r) /\left(1-R^{2}\right) r$. Com base na 
média dos $\eta$ ciclos $(\eta=6)$ e na estimação dos $r$ obtidos de acordo com as diferentes metodologias utilizadas, foi calculado o $\mathrm{R}^{2}$, de acordo com a expressão: $\mathrm{R}^{2}=\eta \mathrm{r} / 1+\mathrm{r}(\eta-1)$

Foram estimados os parâmetros genéticos, representados pela herdabilidade no sentido amplo $\left(\mathrm{h}^{2}\right)$, pelo coeficiente de variação genético $\left(\mathrm{CV}_{\mathrm{G}}\right)$ e pelo índice de variação $\left(\mathrm{b}=\mathrm{CV}_{\mathrm{G}} / \mathrm{CV}_{\mathrm{E}}\right)$, que consideram seis ciclos de avaliação. As análises de repetibilidade e de parâmetros genéticos foram realizadas com auxílio do programa Genes (Cruz, 2006).

\section{Resultados e Discussão}

De modo geral, observou-se que todas as variáveis apresentaram coeficiente de repetibilidade de alta magnitude (médias dos quatro métodos). Os coeficientes de determinação também foram de alta magnitude para todos os caracteres avaliados, o que indica que o modelo matemático adotado ajustou-se satisfatoriamente ao conjunto de dados (Tabela 2).

As variáveis massa de matéria seca de forragem e clorose foliar se destacaram com os maiores valores de r, ou seja, a expressão dessas variáveis apresentou alta regularidade entre os ciclos de avaliação. Já o comprimento do entrenó, apresentou estimativa de $\mathrm{r}$ de média magnitude, o que caracteriza baixa regularidade entre medidas repetidas e evidencia a influência ambiental sobre esta variável. Daher et al. (2004), ao avaliar 16 clones de capim-elefante em 12 ciclos de corte, encontraram valores médios de $r$ inferiores aos observados no presente trabalho para altura da planta $(\mathrm{r}=0,49)$, diâmetro do colmo $(\mathrm{r}=0,65)$ e massa de matéria seca de forragem $(\mathrm{r}=0,38)$, o que mostra a influência do ambiente sobre estas variáveis.
No entanto, Viana et al. (2009) observaram valores superiores de r para altura da planta $(0,80)$ e IAF $(0,90)$, ao avaliar cinco clones de capim-elefante de porte baixo em Itambé, PE, ao longo de cinco ciclos de pastejo de ovinos Santa Inês. É possível que as diferentes idades ontogênicas das plantas, resultantes dos replantios, tenham influenciado essas características e se refletido nos valores de $r$ que, apesar de inferiores, são de alta magnitude.

A partir das estimativas dos coeficientes de repetibilidade obtidas pelos métodos utilizados para cada variável e do coeficiente de determinação, constatou-se que as estimativas obtidas pela ANOVA foram sempre menores do que aquelas obtidas pelos demais métodos. As estimativas obtidas pelo método dos CPCOV foram maiores ou iguais à média geral (Tabela 2), semelhantemente às obtidas pelos outros métodos. Esses resultados são concordantes com a literatura, não apenas para o capim-elefante (Shimoya et al., 2002; Daher et al., 2004), mas também para Panicum maximum (Martuscello et al., 2007; Lédo et al., 2008) e Urochloa ruziziensis (Souza Sobrinho et al., 2010), entre outras espécies. Conforme Cruz \& Regazzi (2001), a análise de repetibilidade pode ser mais eficientemente estimada pelo método dos componentes principais. Assim, o método da ANOVA pode ter subestimado os valores de $r$.

Com o método dos CPCOV seria necessário um ciclo de avaliação para predizer o valor real dos genótipos Pennisetum spp. quanto à massa de matéria seca de forragem e à largura da folha; dois ciclos para comprimento da folha e clorose foliar; e três ciclos para altura da planta, diâmetro do colmo e IAF, se for considerado $\mathrm{R}^{2}=90 \%$ (Tabela 3 ). Nessas circunstâncias, o aumento do número de medições resultaria em

Tabela 2. Estimativas dos coeficientes de repetibilidade (r) e dos coeficientes de determinação $\left(\mathrm{R}^{2}\right)$ para massa de matéria seca de forragem (MF), altura da planta (AP), comprimento (CF) e largura da folha (LF), diâmetro do colmo (DC), comprimento do entrenó (CE), clorose foliar (CFol) e índice de área foliar (IAF) de 16 genótipos de Pennisetum spp. por quatro métodos.

\begin{tabular}{|c|c|c|c|c|c|c|c|c|c|c|c|c|c|c|c|c|}
\hline \multirow{2}{*}{ Método $^{(1)}$} & \multicolumn{2}{|c|}{ MF } & \multicolumn{2}{|c|}{$\mathrm{AP}$} & \multicolumn{2}{|c|}{$\mathrm{CF}$} & \multicolumn{2}{|c|}{ LF } & \multicolumn{2}{|c|}{$\mathrm{DC}$} & \multicolumn{2}{|c|}{$\mathrm{CE}$} & \multicolumn{2}{|c|}{ CFol } & \multicolumn{2}{|c|}{ IAF } \\
\hline & $\mathrm{r}$ & $\mathrm{R}^{2}$ & $\mathrm{r}$ & $\mathrm{R}^{2}$ & $\mathrm{r}$ & $\mathrm{R}^{2}$ & $\mathrm{r}$ & $\mathrm{R}^{2}$ & $\mathrm{r}$ & $\mathrm{R}^{2}$ & $\mathrm{r}$ & $\mathrm{R}^{2}$ & $\mathrm{r}$ & $\mathrm{R}^{2}$ & $\mathrm{r}$ & $\mathrm{R}^{2}$ \\
\hline ANOVA & 0,81 & 0,96 & 0,68 & 0,92 & 0,77 & 0,95 & 0,81 & 0,96 & 0,68 & 0,92 & 0,57 & 0,89 & 0,84 & 0,97 & 0,68 & 0,93 \\
\hline CPCOV & 0,86 & 0,97 & 0,74 & 0,94 & 0,78 & 0,95 & 0,82 & 0,97 & 0,77 & 0,95 & 0,58 & 0,89 & 0,84 & 0,97 & 0,72 & 0,94 \\
\hline CPCOR & 0,84 & 0,96 & 0,73 & 0,94 & 0,78 & 0,95 & 0,83 & 0,97 & 0,74 & 0,94 & 0,61 & 0,91 & 0,85 & 0,97 & 0,70 & 0,93 \\
\hline AECOR & 0,84 & 0,96 & 0,73 & 0,94 & 0,78 & 0,95 & 0,83 & 0,97 & 0,73 & 0,94 & 0,59 & 0,90 & 0,84 & 0,97 & 0,68 & 0,93 \\
\hline Média & 0,84 & 0,96 & 0,72 & 0,94 & 0,78 & 0,95 & 0,82 & 0,97 & 0,73 & 0,94 & 0,59 & 0,90 & 0,84 & 0,97 & 0,70 & 0,93 \\
\hline
\end{tabular}

(1)ANOVA, análise de variância; CPCOV e CPCOR componentes principais, com base na matriz de covariância e de correlação, respectivamente; AECOR, análise estrutural, baseada na matriz de correlação. 
pouco acréscimo na precisão. Portanto, a redução do número de avaliações poderá promover medidas mais rápidas, sem perda na precisão ou na confiabilidade dos resultados (Cruz \& Regazzi, 2001), o que torna essas informações importantes, principalmente na fase inicial do programa de melhoramento, em que é avaliado grande número de clones simultaneamente e a seleção de genótipos superiores deve ser feita de forma mais acurada possível. Cabe ressaltar que poucos ciclos de avaliação não permitem que o pesquisador obtenha informações pormenorizadas sobre a interação genótipo $\mathrm{x}$ ambiente ou sobre o comportamento individual do genótipo frente às variações ambientais.

Ao avaliar a massa de matéria seca de forragem de capim-elefante, com uso do método dos CPCOV, Daher et al. (2004) determinaram que cinco avaliações seriam suficientes para a seleção dos genótipos mais promissores. Para Cargnelutti Filho et al. (2004) e Lédo et al. (2008), em P. maximum, seriam necessárias 14 e 13 avaliações, respectivamente; enquanto para Souza Sobrinho et al. (2010), em U. ruziziensis, seriam necessárias 32 observações. Esses resultados são indicativos de que os valores de $\mathrm{r}$ variaram com

Tabela 3. Estimativa do número de medições $(\eta)$ das variáveis massa de forragem (MF), altura da planta (AP), comprimento (CF) e largura da folha (LF), diâmetro do colmo (DC), comprimento do entrenó (CE), clorose foliar (CFol) e índice de área foliar (IAF) de 16 genótipos de Pennisetum spp.

\begin{tabular}{lccccccccc}
\hline Método $^{(1)}$ & $\mathrm{R}^{2}$ & MF & AP & CF & LF & DC & CE & CFol & IAF \\
\hline \multirow{4}{*}{ ANOVA } & 0,80 & 1 & 1 & 1 & 1 & 2 & 3 & 1 & 2 \\
& 0,85 & 1 & 2 & 1 & 1 & 3 & 4 & 1 & 3 \\
& 0,90 & 2 & 4 & 2 & 2 & 4 & 7 & 2 & 4 \\
& 0,95 & 4 & 8 & 5 & 4 & 8 & 14 & 4 & 9 \\
\hline \multirow{5}{*}{ CPCOV } & 0,80 & 1 & 1 & 1 & 1 & 1 & 3 & 1 & 2 \\
& 0,85 & 1 & 1 & 1 & 1 & 2 & 4 & 1 & 2 \\
& 0,90 & 1 & 3 & 2 & 1 & 3 & 7 & 2 & 3 \\
& 0,95 & 3 & 6 & 5 & 4 & 6 & 14 & 4 & 7 \\
\hline \multirow{5}{*}{ CPCOR } & 0,80 & 1 & 1 & 1 & 1 & 1 & 3 & 1 & 2 \\
& 0,85 & 1 & 2 & 1 & 1 & 2 & 4 & 1 & 2 \\
& 0,90 & 1 & 3 & 2 & 1 & 3 & 6 & 2 & 4 \\
& 0,95 & 3 & 6 & 5 & 3 & 7 & 12 & 3 & 8 \\
\hline \multirow{5}{*}{ AECOR } & 0,80 & 1 & 1 & 1 & 1 & 1 & 3 & 1 & 2 \\
& 0,85 & 1 & 2 & 1 & 1 & 2 & 4 & 1 & 3 \\
& 0,90 & 1 & 3 & 2 & 1 & 3 & 6 & 2 & 4 \\
& 0,95 & 3 & 6 & 5 & 4 & 7 & 13 & 4 & 9 \\
\hline
\end{tabular}

(1)ANOVA, análise de variância; CPCOV e CPCOR, componentes principais, com base na matriz de covariância e de correlação, respectivamente; AECOR, análise estrutural, baseada na matriz de correlação. as propriedades genéticas da espécie e que foram influenciados pelas condições ambientais.

$\mathrm{O}$ baixo número de ciclos de avaliação obtido no presente trabalho pode ser atribuído à matriz de covariância adotada (VC) na análise de medidas repetidas no tempo, que melhor se ajustou ao conjunto de dados, tendo resultado em médias mais uniformes entre os ciclos de avaliação, o que influenciou os valores de r, que foram de alta magnitude (Tabela 2), e, consequentemente, o número de medições. Viana et al. (2009) também relataram que um ciclo de avaliação seria suficiente para selecionar genótipos de Pennisetum spp. quanto às variáveis altura da planta $\left(r=0,80 ; R^{2}=93 \%\right)$ e IAF $\left(r=0,88 ; R^{2}=94 \%\right)$.

A herdabilidade no sentido amplo foi de alta magnitude $(>80 \%)$ para todas as variáveis, conforme classificação proposta por Falconer (1987). Contudo, a menor magnitude foi observada para o comprimento do entrenó (Tabela 4), o que reforça a influência do fator ambiental sobre esta variável. Ao se considerar as variações observadas na precipitação pluvial durante o período experimental (Figura 1), houve variação no comprimento entre os ciclos de avaliação $(\mathrm{r}=0,59$; Tabela 2), o que acarretou em maior número de medições para predizer o valor real dos genótipos (Tabela 3).

Daher et al. (2004) relataram resultados inferiores para massa de matéria seca de forragem, altura da planta e diâmetro do colmo, com $\mathrm{h}^{2}$ de 33, 84 e 75\%, respectivamente. Assis et al. (2010), ao avaliar a produção de 112 híbridos interespecíficos nas formas per se e estratificada, em Itambé, PE, obtiveram valores de $\mathrm{h}^{2}$ de alta magnitude, na ordem de 91 e $86 \%$, respectivamente. Silva et al. (2010), ao analisar 54 clones de capim-elefante, no mesmo

Tabela 4. Parâmetros genéticos para as variáveis massa de matéria seca de forragem (MF), altura da planta (AP), comprimento $(\mathrm{CF})$ e largura da folha (LF), diâmetro do colmo (DC), comprimento do entrenó (CE), clorose foliar (CFol) e índice de área foliar (IAF) de 16 genótipos de Pennisetum spp.

\begin{tabular}{lcccccccc}
\hline Parâmetro genético $^{(1)}$ & MF & AP & CF & LF & DC & CE & CFol & IAF \\
\hline $\mathrm{h}^{2}(\%)$ & 96 & 93 & 95 & 96 & 93 & 81 & 97 & 93 \\
$\mathrm{CV}_{\mathrm{G}}(\%)$ & 38,19 & 8,57 & 16,05 & 16,17 & 16,43 & 7,67 & 6,09 & 7,79 \\
$\mathrm{~b}$ & 0,74 & 0,60 & 0,98 & 1,04 & 0,83 & 0,74 & 1,07 & 0,43 \\
\hline${ }^{(1)} h^{2}$, herdabilidade no sentido amplo; $\mathrm{CV}_{\mathrm{G}}$, coeficiente de variação genéti- \\
co; b, índice de variação.
\end{tabular}


local, encontraram $\mathrm{h}^{2}$ inferiores às do presente trabalho para altura da planta $\left(\mathrm{h}^{2}=47 \%\right)$, diâmetro do colmo $\left(\mathrm{h}^{2}=77 \%\right)$, comprimento $\left(\mathrm{h}^{2}=49 \%\right)$ e largura da folha $\left(h^{2}=78 \%\right)$. No entanto, Silva et al. (2009) observaram, em nove clones de capim-elefante, $\mathrm{h}^{2}$ semelhante quanto às variáveis altura da planta $\left(h^{2}=90 \%\right)$, comprimento da folha $\left(h^{2}=93 \%\right)$, diâmetro do colmo $\left(\mathrm{h}^{2}=98 \%\right)$ e comprimento do entrenó $\left(h^{2}=83 \%\right)$. Do mesmo modo, Cunha et al. (2011), ao avaliar oito genótipos de Pennisetum spp., em Itambé, PE, em quatro ciclos de corte, verificaram $h^{2}(93 \%)$ similar para IAF. Esses resultados são indicativos de que o fator genético das variáveis analisadas variou de acordo com o genótipo, de modo que as informações obtidas são específicas para o grupo genético avaliado.

Segundo Sebbenn et al. (1998), o $\mathrm{CV}_{\mathrm{G}}$ acima de $7 \%$ pode ser considerado alto. Portanto, à exceção da clorose foliar, este parâmetro foi de alta magnitude para as demais variáveis, o que indica ter havido variabilidade genética entre os genótipos avaliados, principalmente em razão das cultivares parentais que são altamente heterozigóticas. O índice de variação, que quantifica a predominância da variância ambiental sobre a genética, só foi favorável à seleção para a variável largura da folha e clorose foliar. Esse índice, quando superior à unidade, indica que o componente genético é pouco influenciado pelo ambiente; portanto, é um caráter indicado para a seleção de genótipos superiores. Esta hipótese é reforçada pelos valores de $h^{2}$ de 96 e $97 \%$, para largura da folha e clorose foliar, respectivamente.

\section{Conclusões}

1. As estimativas dos coeficientes de repetibilidade são de média-alta magnitude para todas as variáveis, quando analisadas pelo método dos componentes principais, baseado na matriz de covariância.

2. Para massa de matéria seca de forragem, altura da planta, comprimento e largura da folha, diâmetro do colmo, clorose e índice de área foliar, até três ciclos de avaliação são suficientes para predizer o valor real dos genótipos de Pennisetum spp. mais promissores; para o comprimento do entrenó, o mínimo é de sete avaliações.

3. Os parâmetros genéticos são de alta magnitude para todas as variáveis avaliadas, e a largura da folha favorece mais eficientemente a seleção de genótipos superiores, em razão da baixa influência do fator ambiental sobre esta variável.

\section{Referências}

ASSIS, L.C. da S.L.C.; LIRA, M. de A.; SANTOS, M.V.F. dos; DUBEUX JÚNIOR, J.C.B.; CUNHA, M.V. da. Estimativa de parâmetros genéticos sob duas estratégias de avaliação em híbridos intra e interespecíficos de capim-elefante. Revista Brasileira de Zootecnia, v.39, p.2589-2597, 2010.

BELTRÃO, B.A.; MASCARENHAS, G. de C.; MIRANDA, J.L.F. de; SOUZA JÚNIOR, L.C. de; GALVÃO, M.J. da T.G.; PEREIRA, S.N. Projeto cadastro de fontes de abastecimento por água subterrânea, Estado de Pernambuco: diagnóstico do Município de Itambé. Recife: Ministério de Minas e Energia, 2005. 22p.

CARGNELUTTI FILHO, A.; CASTILHOS, Z.M. de S.; STORCK, L.; SAVIAN, J.F. Análise de repetibilidade de caracteres forrageiros de genótipos de Panicum maximum, avaliados com e sem restrição solar. Ciência Rural, v.34, p.723-729, 2004.

CAVALCANTE, M.; LIRA, M. de A. Variabilidade genética em Pennisetum purpureum Schumacher. Revista Caatinga, v.23, p.153-163, 2010.

CRUZ, C.D. Programa Genes: biometria. Viçosa: UFV, 2006. $382 \mathrm{p}$.

CRUZ, C.D.; REGAZZI, A.J. Modelos biométricos aplicados ao melhoramento genético. 2.ed. Viçosa: UFV, 2001. 390p.

CUNHA, M.V. da; LIRA, M. de A.; SANTOS, M.V.F. dos; FREITAS, E.V. de; DUBEUX JUNIOR, J.C.B.; MELLO, A.C.L. de; MARTINS, K.G.R. Association between the morphological and productive characteristics in the selection of elephant grass clones. Revista Brasileira de Zootecnia, v.40, p.482-488, 2011.

DAHER, R.F.; MALDONADO, H.; PEREIRA, A.V.; AMARAL JÚNIOR, A.T. do; PEREIRA, M.G.; FERREIRA, C.F.; RAMOS, S.R.R.; TARDIN, F.D.; SILVA, M.P. da. Estimativas de parâmetros genéticos e de coeficientes de repetibilidade de caracteres forrageiros em clones de capim-elefante (Pennisetum purpureum Schum.). Acta Scientiarum Agronomy, v.26, p.483-490, 2004.

FALCONER, D.S. Introduction to quantitative genetics. 2.ed. London: Longman, 1987. 340p.

FERREIRA, R.P.; PEREIRA, A.V. Melhoramento de forrageiras. In: BORÉM, A. (Ed.). Melhoramento de espécies cultivadas. Viçosa: UFV, 2005. p.781-812.

INSTITUTO DE TECNOLOGIADE PERNAMBUCO. LAMEPE: banco de dados pluviométricos do Município de Itambé. Disponível em: $<$ http://www.itep.br/index.php?option=com_content\&view=ar ticle\&id=474\&Itemid=387>. Acesso em: 28 set. 2011.

LÉDO, F.J. da S.; PEREIRA, A.V.; SOUZA SOBRINHO, F. de; AUAD, A.M.; OLIVEIRA, J.S. e. Estimativas de repetibilidade para caracteres forrageiros em Panicum maximum. Ciência e Agrotecnologia, v.32, p.1299-1303, 2008.

LIRA, M. de A.; CUNHA, M.V. da; PEREIRA, A.V. Melhoramento genético do capim-elefante. In: LIRA, M. de A.; SANTOS, 
M.V.F. dos; DUBEUX JÚNIOR, J.C.B.; MELLO, A.C.L. de (Ed.). Capim-elefante: fundamentos e perspectivas. Recife: IPA: UFRPE, 2010. p.31-48.

MARTUSCELLO, J.A.; JANK, L.; FONSECA, D.M. da; CRUZ, C.D.; CUNHA, D. de N.F.V. da. Repetibilidade de caracteres agronômicos em Panicum maximum Jacq. Revista Brasileira de Zootecnia, v.36, p.1975-1981, 2007.

MORAIS, R.F. de; SOUZA, B.J. de; LEITE, J.M.; SOARES, J.H. de B.; ALVES, B.J.R.; BODDEY, R.M.; URQUIAGA, S. Elephant grass genotypes for bioenergy production by direct biomass combustion. Pesquisa Agropecuária Brasileira, v.44, p.133-140, 2009.

PACIULLO, D.S.C.; DERESZ, F.; AROEIRA, L.J.M.; MORENZ, M.J.F.; VERNEQUE, R. da S. Morfogênese e acúmulo de biomassa foliar em pastagem de capim-elefante avaliada em diferentes épocas do ano. Pesquisa Agropecuária Brasileira, v.38, p.881-887, 2003.

RESENDE, M.D.V. de. Genética biométrica e estatística no melhoramento de plantas perenes. Brasília: Embrapa Informação Tecnológica; Colombo: Embrapa Florestas, 2002. 975p.

SANTOS, D.C. dos; LIRA, M. de A.; DUBEAUX JÚNIOR, J.C.B. Capineira de Pennisetum purpureum Schum. In: CAVALCANTI, F.J.A. (Ed.). Recomendação de adubação para o Estado de Pernambuco: $2^{a}$ aproximação. 3.ed. Recife: IPA, 2008. p.136.

SAS INSTITUTE. SAS/STAT: user's guide for MIXED procedure. Version 9.2. Cary: SAS Institute, 2008. 224p.

SEBBENN, A.M.; SIQUEIRA, A.C.M. de F.; KAGEYAMA, P.Y.; MACHADO, J.A.R. Parâmetros genéticos na conservação da cabreúva (Myroxylon peruiferum L.F. Allemão). Scientia Forestalis, v.53, p.31-38, 1998.

SHIMOYA, A.; PEREIRA, A.V.; FERREIRA, R. de P.; CRUZ, C.D.; CARNEIRO, P.C.S. Repetibilidade de características forrageiras do capim-elefante. Scientia Agricola, v.59, p.227-234, 2002.

SILVA, A.L.C. da; SANTOS, M.V.F. dos; FERREIRA, R.L.C.; DUBEUX JÚNIOR, J.C.B.; LIRA, M. de A.; CUNHA, M.V. da; PEREIRA,A.V.; ARAÚJO, G.G.L.de. Variabilidade eherdabilidade de caracteres qualitativos relacionados à qualidade de forragem de clones de capim-elefante na Zona da Mata de Pernambuco. Revista Brasileira de Zootecnia, v.40, p.39-46, 2010.

SILVA, S.H.B. da; SANTOS, M.V.F. dos; LIRA, M. de A.; DUBEUX JÚNIOR, J.C.B.; FREITAS, E.V. de; FERREIRA, R.L.C. Uso de descritores morfológicos e herdabilidade de caracteres em clones de capim-elefante de porte baixo. Revista Brasileira de Zootecnia, v.38, p.1451-1459, 2009.

SOUZA SOBRINHO, F. de; BORGES, V.; LÉDO, F.J. da; KOPP, M.M. Repetibilidade de características agronômicas e número de cortes necessários para seleção de Urochloa ruziziensis. Pesquisa Agropecuária Brasileira, v.45, p.579-584, 2010.

VIANA, B.L.; MELLO, A.C.L. de; LIRA, M. de A.; DUBEUX JÚNIOR, J.C.B.; SANTOS, M.V.F. dos; CUNHA, M.V. da; FERREIRA, G.D.G. Repetibilidade e respostas de características morfofisiológicas e produtivas do capim-elefante de porte baixo sob pastejo. Pesquisa Agropecuária Brasileira, v.44, p.1731-1738, 2009.

Recebido em 28 de novembro de 2011 e aprovado em 17 de março de 2012 